\title{
From the ergonomic guidelines to the configuration of use in the offshore platforms design context
}

\author{
Cláudia Vieira Carestiato Cordeiro ${ }^{\mathrm{a}}$, Barbara de Macedo Passos Oggioni ${ }^{\mathrm{a} *}$, \\ Francisco Jose Castro Moura Duarte ${ }^{\mathrm{a}}$, Francisco de Paula Antunes Lima ${ }^{\mathrm{b}}$ \\ ${ }^{a *}$ Universidade Federal do Rio de Janeiro, Rio de Janeiro, RJ, Brasil, \\ bmpoggioni@gmail.com \\ bUniversidade Federal de Minas Gerais, Belo Horizonte, MG, Brasil
}

\begin{abstract}
The possibility of using pre-defined ergonomic recommendations for projects offshore is related to several factors that encompass the hiring of a specialized ergonomic team to the design phase in which this team is involved in the context of the project. The main objective of this article is to test the usage and discuss the applicability of the Ergonomic Technical Recommendations (TRs), developed using the Ergonomic Work Analysis methodology. Although the TR files were considered overly long to read/become familiarised, the contextualization of the TRs through the configurations of use and the ergonomic study, or the "specialists", were fundamental in leading the ergonomic directives to being considered and implemented.
\end{abstract}

Keywords

Ergonomic design. Ergonomic Work Analysis. Project.

\section{Introduction}

There have been several recent studies in the field of ergonomics with the aim ofstandardising the implementation of ergonomic specifications in major engineering projects. The main focus of these studies has been to offer ergonomic criteria for large-scale projects and to thus improve work spaces and provide more efficient operation. However, despite these studies, there is still relatively little known of designers' views on and usage of these criteria and, therefore of whether they are actually effective in achieving their proposed objectives (Wulff et al., 1999a).

Studies that have focused on the use of ergonomic standards in design projects show the limitations and difficulties that engineers have in finding the information they need when consulting these specifications. These difficulties involve the large number of technical specifications and directives that need to be met in large-scale projects and which are more numerous than engineers' ability to process them all, and the formulation of the standards, which are often considered overly generic and hard to apply to a project's specific situation (Westgaard \& Wulff, 1991; Wulff et al., 1999a, b; Conceição, 2011).
In this context, between 2008 and 2009, the COPPE/ UFRJ Product Engineering Program, in partnership with the research centre of a Brazilian oil company, developed the study "A integração da ergonomia ao projeto de plataformas offshore" [The integration of ergonomics with design projects for offshore platforms] (Duarte et al., 2009a). The study's central aim was to draw up ergonomic technical recommendations (TRs), which would act as directives for the basic design of the oil company's future platforms. The methodology used for the study was the Ergonomic Work Analysis - EWA (Guérin et al., 2001). The study resulted in configurations of use and ergonomic recommendations for the design of new oil platforms, both for the accommodation modules and for the operation areas, and it sought to extract a set of principles from the reality of work situations, in order to facilitate the application of the TRs by future designers of these units.

In 2010, the need for a new ergonomic study for the detailing stage of the design of two new platforms for the same company (PROJ-A and PROJ-B), offered an opportunity to test the usage and discuss the 
applicability of the recommendations drawn up in the previous project, and it is this study that is the main focus of the present article.

\section{Ergonomics of design: ergonomic practice in the design of new installations}

The dialectics of design as a permanently evolving conversation between designer and user mediated by the tool and the activity, or rather, by instrumental activity (Béguin, 1994) are already familiar. There are many challenges to drawing up technical recommendations, and there are numerous issues at stake as the object of them is a future activity that does not yet exist, and is only based on specific knowledge of similar current situations that can be analysed (a paradox of design ergonomics). In addition to this, each project has its own life-cycle and undergoes numerous transformations between the initial feasibility study phase and actual use (Cordeiro, 2003; Castro, 2010).

Since its beginnings, the aim of ergonomics has been to provide recommendations for design engineers to incorporate human factors into design projects. In large-scale technological projects, ergonomic involvement is on the increase, as a complex productive system brings problems that require cooperation between several fields of knowledge and expertise.

Ergonomic knowledge of human functioning and relationships to objects, environments and work tools has been described in manuals (Grandjean, 1998; lida, 1990; Salvendy, 1982) that are aimed at providing a foundation for engineering projects. However, one must question the actual help that Human Factors manuals are able to offer design engineers when faced with complex systems. In general, the manuals set out properties and parameters for the relationships between several human functions (such as sight, hearing and anthropometrics) and specific aspects of work environments (such as colour, lighting, space and size of work posts and equipment), thereby defining parameters of comfort and efficiency in accordance with certain features of tasks. Although there are a significant number of accumulated facts and empirical recommendations in these manuals and in technical norms, there are some principles in these manuals that are clear.

The suggested parameters tend to correlate the physical-mechanical properties of tools with certain generic human physiological and anthropometric characteristics, more directly implicated with the physical system and generally associated with "ideal conditions", such as those in laboratories. Thus, despite a model being fairly sophisticated in physiological terms, it will always have its limitations, as it ignores other determining factors of work situations and of the context in which it evolves.

By taking into account general characteristics of tasks and of those performing them, the idea is to create a general knowledge set that can be applied at any stage of a project. Wulff et al. (1999b) suggest the preference of designers for exact specifications that can be directly applied, like those found in manuals. However, in practice, designers should deal with individual problems, that involve a series of variables related to the specific features of the work population, the installations, the operating and maintenance conditions, and the complete context surrounding the activity, so the direct application of specific formulae may act as a barrier to developing and creating new more suitable solutions.

In industry, as well as the variables surrounding variations in the quality of raw materials and variations in environmental conditions, there is also considerable wear and tear of equipment and sometimes aggressive environments (as on oil platforms) that can affect the functioning and reliability of sensors and control systems (Duarte, 1994) and that may lead to less effective functioning (Daniellou \& Garrigou, 1991; Duclos, 1991). The functioning of industrial installations ultimately rests on both individual strategies (information gathering, reasoning, diagnostics and prognostics etc.) and collective strategies (communications, information exchange, coordination of actions etc.) developed by operations and maintenance teams (De Keyser et al., 1988; Wisner, 1990; Llory, 1996; Neuville, 1997). As far as possible, these strategies seek to manage the different forms of industrial variations and to anticipate the consequences of chance events in order to avoid untoward incidents and accidents. In most cases, in the short term, installations' operational performance is maintained, but this does not mean, however, that there may not be a significant cost to operators' health (Garrigou et al., 1994).

In the designs, a lack of consideration of these variables and of operators' needs, may lead to direct consequences on the installations' operating conditions: unexpected delays, high production and maintenance costs, risk of accidents, absenteeism, training difficulties, etc. On oil platforms for example, a greater need for human intervention signifies a greater POB - People On Board, which then signifies higher production costs and raises safety questions for those on board. In addition to this, modifications and repairs to offshore installations are hard to execute and extremely costly.

The difficulties in driving projects and operating problems for production units show clearly the 
need to better understand operators' individual and collective activities when using industrial installations (Béguin, 1994; Rabardel, 1995). The approach used to generate the TRs for the future oil platforms was founded on this understanding of use and aimed to underpin the design process, and it was based on the kind of ergonomics that focuses on the work activity as a study object.

This approach, which can be characterised as ascending or "bottom-up", departs from the principle that a consideration of the conditions for performing the task from the initial phases of a project can support the choices made for the design of the technical systems and work stations. It is a complementary approach to a descending, or "top-down" approach, where the major technical options, principle flows and bottlenecks are only defined after the definition of the production aims and required investment. Although, in the "top-down" approach, many engineers and designers are convinced of the importance of being aware of the functioning and needs of future users, this actually only occurs in the final design phases, at the time the features of the human-machine interfaces and work stations are defined (Maline, 1994).

A combination of the two approaches in the early phases of projects allows the description and comprehension of the inter-relationships between projects' different components, enabling a greater ability to anticipate problems and reducing uncertainties about the efficiency of future operations throughout the entire design process. This global approach to the concept is ever more necessary in the face of the complexity and rising costs of the work systems that are currently designed for offshore platforms.

\section{The elaboration of technical recommendations for projects in the context of activity ergonomics}

The study made by Duarte et al. (2009a) aimed to intervene in the basic design phase, and integrate ergonomic principles and recommendations from analysis of the actual work situations, thereby involving the work dimension right from the outset of the design of the new platforms. The aim was to create installations that were more suited to production and to users, while applying health, security and efficiency criteria. At the same time, the study attempted to systematize the company's experience in the design and in the operation of offshore platforms, which was at the time still in its early stages.

The study prioritized the needs that were raised in actual work situations on six functioning platforms, and compared them with the recommendations in the bibliography. Based on the analysis of specific situations and more generic design specifications, which were critically assessed in the light of the observations of reference situations, recommendations in the form of technical specifications were formulated for several environments, areas and equipments in the designs.

The activity analyses were concentrated on a principal reference situation: the REF-1 platform. These analyses were compared with the design solutions adopted on another five platforms to validate the analyses and thereby either generalize them or limit their relevance to particular situations. This made it possible to formulate recommendations that encompassed a wider range of experience, and that could indicate relationships between particular design philosophies and recommendations for specific solutions.

The duration of the project was 30 months and its main products were documents that included: (1) Mapping of critical situations (regarding workload) for the REF-1 operating teams; (2) Ergonomic work analyses of the accommodation module; (3) Ergonomic work analyses of the processing area; (4) Ergonomic technical recommendations for offshore platform design - accommodation module; (5) Ergonomic technical recommendations for offshore platform design - processing area; (6) Technical recommendations for the control rooms of the six platforms analysed as reference situations; and (7) Technical recommendations to improve work conditions on the REF-1 platform.

The aim of the first five documents was to serve as a base for the new platforms' design, and was in the framework of design ergonomics. The remaining two documents had a more immediate aim, which was to offer specific ergonomic recommendations to improve working conditions in several critical situations on REF- 1 and in the control rooms of the other platforms that were visited, and this was therefore in the framework of correctional ergonomics.

The content of the TRs for the new platforms' design was gradually and collaboratively drawn up, in an attempt to take advantage of the company designers' experience in social and technical construction. Therefore, initial versions of the TRs were used as the base for analyses, discussions, criticisms, suggestions and validation by the range of participants involved in the project - operators, coordinators and designers.

In 2010, the design for the PROJ-A and PROJ-B platforms required an ergonomic study, and this gave the opportunity to test the TRs, that had been produced, in a new project, to verify their effectiveness, and to see if any improvements could be made. 


\section{Technical recommendations, technical configurations and configurations of use: tools to be tested}

The main issue in drawing up the TRs in the project of Duarte et al. (2009a) was that the recommendations were expected to be more general, and not to be bound to specific cases, even when the reference situation was a good example for use. For this, the concept of configuration of use contributed towards these recommendations taking on the role of a reference, and not an obligatory standard, thus leaving room for manoeuvre for the design team to innovate and even improve on existing solutions.

Without defining or detailing the project, the configurations of use bring together physicaltechnological aspects (space, object, equipment...) and social context and cognitive guidance (e.g.: "to transport food to...") in a practical plan that underpins a given activity, or rather, they extract the existing relationships between the space and the activity performed in it. In this way the information about use is provided to the designer as well as its implications for the space (Duarte et al., 2008, 2009b; Conceição \& Duarte, 2010). As they are more general, the configurations of use can remain separate from the variables and specificities of each platform, the details of the process and operating practices, and specific problems.

In the TRs, the typical work situations can be divided into two groups: one that includes the activity, another that only considers the relationships between material elements. The criterion that distinguishes these groups is the activity: in one case, the thing that creates the situation, the relationships between the things and/or people present, is a human action, a subject developing an activity; in the other case, the relationships are resolved between the things themselves. At the point of designing a system, both relations (named "configurations of use"; and "technical configurations" respectively) should be considered by engineers. Certain technical configurations can be transformed into configurations of use if a human presence manifests into an action.

It should be noted that ergonomic TRs are not the same as technical norms which are mandatory to follow. To avoid limiting designers' activities, attempts have been made to show the reasoning behind each of the TRs. The idea of configurations of use helped to situate the recommendation in the context of the activity itself, and in its objective/ purpose or the problem to be solved. Whenever possible, design parameters were set out, explaining the reasoning, and how to calculate and/or show them within familiar reference situations. Thus, the recommendations sought to encompass what to do, why to do it, and to an extent, how to do it.

The TRs in Duarte et al. (2009a) did not at any time intend to substitute ergonomic actions required during the development of the new projects; rather they sought to guide the design process so that work variables were considered from the outset. The TRs are for the specialists in the design teams and also for the ergonomists, who may, especially over the initial design phases, use them as a guide for their actions and interactions with other specialists, as they demonstrate the critical design aspects of the work conditions of future operators.

\section{A new project: an opportunity to evaluate the use of technical recommendations in a practical situation}

A design project is the materialization of technical, economic, cultural, and socio-political factors, and does not result only in technical specifications. The company's strategic directives in force, whether explicit or implicit, were a particularly important factor of the platform design, and had direct repercussions on the content of the design recommendations.

At the time of the initial study (2008-2009), there were several strategic directives that influenced certain recommendations, and it was assumed that as the directives changed, recommendations would also change or become invalid, examples being the impact of drilling in new oil fields with features distinct from existing fields, and differing policies for maintaining and supplying units.

The design context of the new PROJ-A and PROJ-B platforms in 2010 was different from the one in force in the company at the time the recommendations were drawn up. The new project direction encompassed changes which would significantly influence on-board activities such as the reuse of ships' installations (previously only the ship's hull was reused); the reduced POB (the aim to reduce the number of people on board by half); construction phases to be carried out in different and distant countries (Brazil and abroad) with emphasis on the detailing phase; and the ergonomics team's involvement only at the project's detailing phase (the TRs were drawn up to guide the basic design phase). These changes made it possible to evaluate how the TRs, which had been created at a given moment, could be incorporated into new projects over time.

The Brazilian oil company was responsible for the basic design of the two platforms (PROJ-A and PROJ-B) and subcontracted the detailing phase to a design firm. The ergonomic study contracted by the outsourced design firm was supposed to 
generate recommendations for the detailing and construction phases, which were divided into a further two phases. The first, with the detailing and construction undertaken abroad, encompassed everywhere in the accommodation area, including the galley, mess room and provision store; the hospital; offices; meeting rooms and technical library; catering/ kiosk office; cabins, bathrooms and changing rooms; laundry; gym and reception, but not the control room (operating and equipment environments) or the radio and telecommunications' rooms. The second phase encompassed the detailing and execution stage in Brazil, and included the areas of the control room and radio and telecommunications rooms; workshops; warehouses; laboratory and the electric panel and instrumentation rooms.

The schedule initially set for the ergonomic study began with the two phases for PROJ-A, followed by the two phases for PROJ-B. Over the course of the study, there was an inversion of phases in an attempt to increase the ergonomic study's range of action in the first phase of PROJ-B, as its detailing and execution had still not begun. The schedule can be seen in the Figure 1.

For each of the major phases above, the ergonomic study made an analysis and overview of the two platforms' basic design so as to subsequently be able to propose ergonomic alternatives and recommendations. Throughout these stages, the ergonomic study set up meetings for different participants in the project so as to enable information exchange between the different viewpoints and perspectives and to negotiate alternatives and validate any proposed changes:

- The ergonomic study team: composed of four ergonomists from the Ergonomics and Design group in the Production Engineering Program at COPPE - UFRJ.
- The team of designers responsible for detailing: represented by the group of architects and engineers from the subcontracted firm responsible for the detailed project. The architecture team was responsible for managing and bringing together the architectural project with that of ergonomics and other areas, which among others included telecommunications, air conditioning, transportation of shipments, automation, and security.

- The basic design team: comprised of the architects from the Brazilian oil company who undertook the basic design of the two platforms.

- The team of end users: represented by the future users of the platforms (future maintenance and production managers). These were responsible for approving the proposals and for providing information on the reality of work and life on board.

The aim of the design overview was to verify the suitability of the initial layout with the characteristics of the activities performed in the environments looked at. This phase detected the main differences between the initial design and the TRs described in Duarte et al. (2009a). The differences between what was planned for the design and the recommendations based on the actual activity were classified into three problem areas: (1) issues related to location, access and flows; (2) issues related to sizing and layout; and (3) issues related to furnishings, equipment, devices and installations.

Based on the analysis and classification of the problems, the needs identified in the reference situations were brought into line with the design for the PROJ-A and PROJ-B platforms according to each environment. This made it possible to build an understanding of the design and its restrictions, and led to proposed modifications of the layouts, which were eventually approved by those involved in the project.

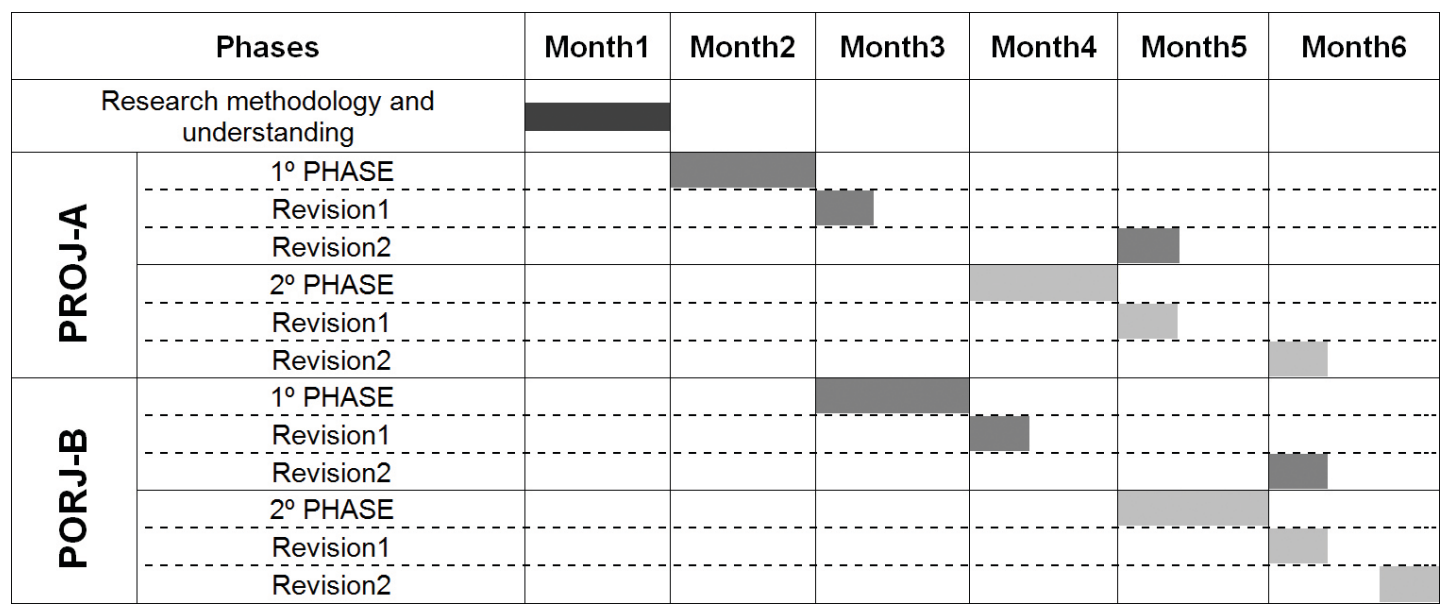

Figure 1. Ergonomic study schedule for the designof the PROJ-A and PROJ-B platforms. 
The use of TRs in the project was mapped out for each environment. When it was not possible to use the TRs due to the restrictions and specificities of the design of the two new platforms, the attempts to bring the project into line ergonomically used the configurations of use in Duarte et al. (2009a) as their main reference, and these acted as guidelines for configuring the new environments for the activities performed in each. The participation of all those involved in the project - end users and designers - also contributed towards a better understanding of specificities that need to be considered.

Analysis of the use and potential uses of the ergonomic recommendations for PROJ-A and PROJ-B enabled an understanding of the attempts to resolve the differences between what had initially been designed in the basic project and what the activity performed in these environments demands in practice. This provided a base for discussion about the possibility of using TRs in a real design situation, even if it were in a different design context.

At the end of the project, the results were discussed and approved with the detailing team. The following example is for this application for the project's control room.

\section{The example of the control room}

The control room is the site of continuous remote activities that operate the production systems, facilities, and automation and navigation systems (for FPSOs). Activities undertaken by operators in the control room include the permanent surveillance of the information system that controls operating variables and a range of actions to maintain the system's normal operations, which are performed at regular intervals by automatic systems or by field operators.

The support areas for the control room and for the operational team's activities, such as office areas, meeting rooms, video-conference rooms, the technical library, snack areas and even the bathrooms are essential for providing the necessary level of support for operators. The proximity of those rooms to each other and in relation to the control room is important not only for the daily activities that are necessary, but also particularly in crisis situations, when the need for interaction between technicians and managers and operators is greater and more frequent. According to Duarte et al. (2009a), there are several configurations of use for a platform control room shown in Table 1.

From understanding the environment's configurations of use, an attempt was made to use the TRs, described in the same study, for the PROJ-A and PROJ-B projects. The Figure 2 shows the degree the TRs were used for the design of the control room and its support areas considering location, access, flow, layout, furnishings and equipment. So as to facilitate discussion about the use of the recommendations in the accommodation design of the platforms studied, they were classified as follows: (1) viable for application to the design and applied (2) viable for application, but not applied; and (3) unfeasible for application.

As can be seen in the graph below, the difficulties in using the recommendations in relation to the location of the environments arose from the cost that modifications would generate in the detailing

Table 1. Examples of configurations of use related to the control room and support areas. Source: Duarte et al. (2009a).

\begin{tabular}{|c|c|c|}
\hline Use & Place & Description \\
\hline General use & $\begin{array}{l}\text { Operational environment - } \\
\text { Operational consoles }\end{array}$ & $\begin{array}{l}\text { Monitoring, control and operation of valves, devices and equipment remotely and in } \\
\text { constant communication with the fieldteam. }\end{array}$ \\
\hline $\begin{array}{l}\text { General shut } \\
\text { down }\end{array}$ & $\begin{array}{l}\text { Operational environment - } \\
\text { Operational consoles (production/ } \\
\text { facilities) }\end{array}$ & $\begin{array}{l}\text { When there is a break in gas production and the "processing plant shuts down", the } \\
\text { gas generators should switch over to operating on diesel. } \\
\text { In this situation, the facilities team should activate the generators so that the } \\
\text { production team can become operational again and direct gas to the generators and } \\
\text { thereby re-stabilize production. This situation may require the presence of supervisors } \\
\text { and, in some cases, the unit management, as there is a strong interaction between the } \\
\text { production team sand facility teams in the control room. }\end{array}$ \\
\hline $\begin{array}{l}\text { Adjustments } \\
\text { to the sensor } \\
\text { readings }\end{array}$ & $\begin{array}{l}\text { Operational environment - } \\
\text { Operational consoles (production } \\
\text { or facilities/automation) }\end{array}$ & $\begin{array}{l}\text { When the production or facilities operators from the control room identify a } \\
\text { discrepancy between the automatic sensor reading and the actual measurements } \\
\text { confirmed by field operators, the automation team need to intervene in order to } \\
\text { make the necessary adjustments and to reset the correct readings. In these cases, the } \\
\text { automation technician collaborates with the productionor facilities operator at their } \\
\text { respective consoles. }\end{array}$ \\
\hline $\begin{array}{l}\text { 1ssuing of Work } \\
\text { Permits (WPs) }\end{array}$ & Operating environment & $\begin{array}{l}\text { Maintenance activities need to be authorized by the field operator responsible for the } \\
\text { relevant area, who will issue a WP. These authorisations require forms to be filled out } \\
\text { and, in the event of any kind of risk, they must be completed only after consulting the } \\
\text { system via computer and, in certain situations, after evaluation by other sectors. } \\
\text { If there is not a designated place for this daily activity, the control room isused, which } \\
\text { in general disrupts the operating environment. }\end{array}$ \\
\hline
\end{tabular}




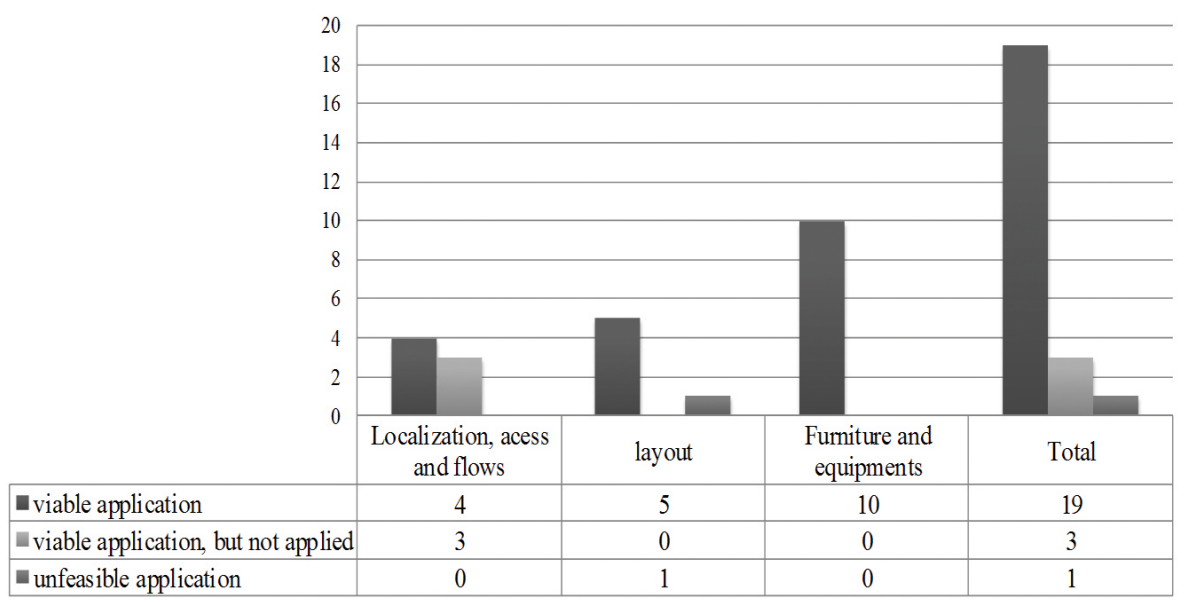

Figure 2. Possible utilization of ergonomic recommendations in control room design.

phase in which the ergonomic study was involved. In the layout, the difficulty of applying the TRs was mainly related to the restrictions imposed by reuse of the ship's installations.

One important fact that impacted on the project of both platforms was the lack of definition on the work organization.

I have already tried to know how will that organization be, but nobody can answer. Nowadays we work in distinct ways, but the maintenance and facilities staff will probably get together.

Taking the users point of view into consideration, the ergonomic study adopted the strategy of adapting the layout to different possible configurations. Even with the extinction of the facilities team, working stations for the operator were considered in the control room, yet being part of another staff.

Another important issue was the limitation of the area of the control room which could not exceed 74 $\mathrm{m}^{2}$. According to the designers, "[...] this number was copied from another platform, it is not necessarily a number that will suit to other situations." On this parameter, any proposal of enlargement of the control room was limited. The image in Figure 3 shows the proposed layout for the basic design and the modifications introduced from the ergonomic study in the control room.

\section{Results}

The ergonomic team's participation in the two platforms' design process facilitated a social connection between all the teams, and integrated their different logics into the process as a whole. When professionals respond to indeterminate areas of practice and hold reflexive conversations on the materials involved in their situations, they recreate part of their practical world and thereby reveal the normally tacit construction processes of a vision of the world on which they base their entire practice (Schön, 2000). From the start of this project an attempt was made to reflexively register the collection of material remains - floor plans, minutes from meetings, field notebooks, etc. - in order to build a physical memory of the project.

The reconstruction of these memories allowed different reflections on the design practice, and initiated discussion of the use of the TRs proposed in Duarte et al. (2009a). When describing the difficulties encountered in applying ergonomics to the project, there was an attempt to test and discuss to what extent the knowledge of the operating platforms used as references was useful and helpful for designers in different design contexts. These considerations have been categorized and presented in the following two types.

\subsection{Reflection on the choices of the design solutions}

Validation of the design histories of PROJ-A and PROJ-B with the design detailing team made it possible to reflect on the reasons for the choices of layout options suggested by the ergonomic study made by the oil company that would be operating the PROJ-A and PROJ-B platforms. This in turn made it possible to identify the main barriers to applying the TRs. From this reflection, it was then possible to categorize these "reasons" as follows:

Detailing and construction linked to the basic project. "The company [foreign, responsible for detailing and construction] followed the basic design 


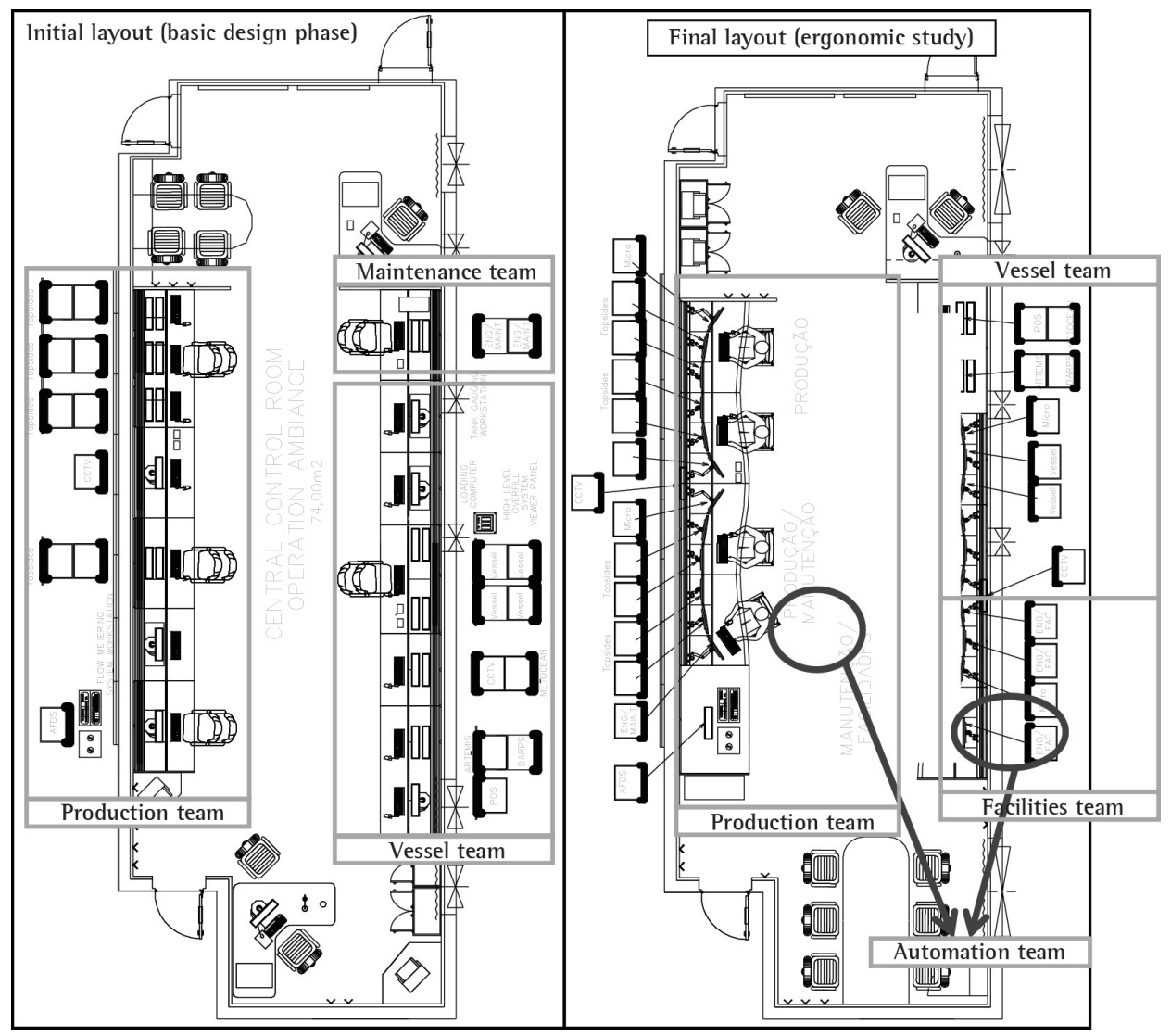

Figure 3. Initial layout proposed by the basic design and the modifications proposed by the ergonomic study.

plan, as it was contractually obliged to do so"; any modification would generate extra alteration costs for the oil company, whose priority was to cut costs.

Aware of this contractual responsibility, it was up to the managers of each project (PROJ-A and PROJ-B) to evaluate whether the proposed modifications were actually viable, and whether to absorb the impacts of the extra costs.

Bringing phases together, thereby allowing some simultaneity between the detailing of the design and its construction. There was some simultaneity between the detailing and construction phases, which was the result of bringing together the design phases, and which used the basic design as an information source for the construction phase; this complicated the approval of modifications to the detailing in areas that had already been completed.

Design directives and parameters. In addition to the new design "philosophy" that governed the company's platform design and specifically the designs for PROJ-A and PROJ-B, certain parameters were established for the project, one of which was cost control. The so-called "fuse parameters" functioned as indicators for the design: if any parameter is exceeded, this is an indicator that the "fuse" is about to blow. Each discipline had its "fuse parameters", the majority involved restrictions in order to cut costs, however some involved the company's new policies on reducing the number of people on-board. In the case of the architectural and ergonomic study, there were two parameters of this nature: all the habitable rooms could only have a maximum of $19 \mathrm{~m}^{2}$ per person; and the area of the control room could not exceed $74 \mathrm{~m}^{2}$, which restricted all proposals to expand them from the outset of the ergonomic study.

\subsection{Reflection on the platforms' design process based on new design guidelines}

The ergonomic team's contact with the different teams involved in designing PROJ-A and PROJ-B, and the subsequent approval of the information identified, made it possible to reflect on the design process using the views of the designers themselves on the new design guidelines for the two projects, particularly as it was not possible to access the new design directives that had guided the basic design. These viewpoints were categorized as follows: 
Main design characteristics of the reuse of ships for oil platforms (Floating production storage and offloading vessels [FPSOs]). The reuse of vessels is a common practice, but it does to some extent have an impact on the design of the new installation, due to already existing features. Several factors, such as ceiling height and size of environments, may be affected. The reuse of existing environments is relatively common-place, despite the fact that they do not always meet the needs of operators and other platform workers.

Views of the detailing process. The detailing process of some of the platform environments was the responsibility of the foreign shipyard, which proceeded using the basic design project. The ergonomic study for this same phase was ongoing in Brazil, and this caused considerable difficulty in implementing the proposals, as the time for modifications had already passed and the impact on costs would have been significant.

The first phase of PROJ-B was postponed in order to try to solve this problem found in the first phase of PROJ-A, as a series of inconsistencies in the basic design had been identified. The aim of the strategy adopted was to win time so as to be able to implement all the recommendations.

Length of project and margin of manoeuvre for modifications. There are few possibilities of modification when the length of the project is reduced to a minimum, and this limited the efficacy of the ergonomic study. In previous experiences, the entire project was designed first and then executed. In the PROJ-A and PROJ-B designs there was significant parallelism between the design phases. Additionally, and possibly because of, the reduction in the time given to develop each phase, the design detailing and the execution phase took place in the most part simultaneously. For the designers this had disadvantages, as it reduced chances to make adjustments, which were on occasion necessary in order to meet the needs of the design.

From reflection on the choices made in the detailing phase of PROJ-A and PROJ-B, it was possible to identify the main areas of difficulty in applying the TRs, and the main impacts of the company's change of philosophy on the design process from the viewpoint of the designers.

Therefore as shown in the control room, other environments of the accommodation modules of the platforms also brought this issues out for debate about difficulty in applying the TRs. At the areas that are part of the feeding sector (galley, bakery, mess room, barbecue and provisions), for example, one important recommendation is an integrated project, considering its interconnected operation. Thus, one should prioritize solutions that put these areas on the same floor. However, the project had the restriction of reusing some areas of the old ship, preventing the use of this recommendation. The ergonomic study offered alternative layouts for the galley in order to reduce the impact of this movement in their activities.

The graph in Figure 4 shows a mapping of the use of the recommendations in the designs for the accommodation units on platform PROJ-A. One can see that the viability of using the recommendations in the environments here shown is high, even considering

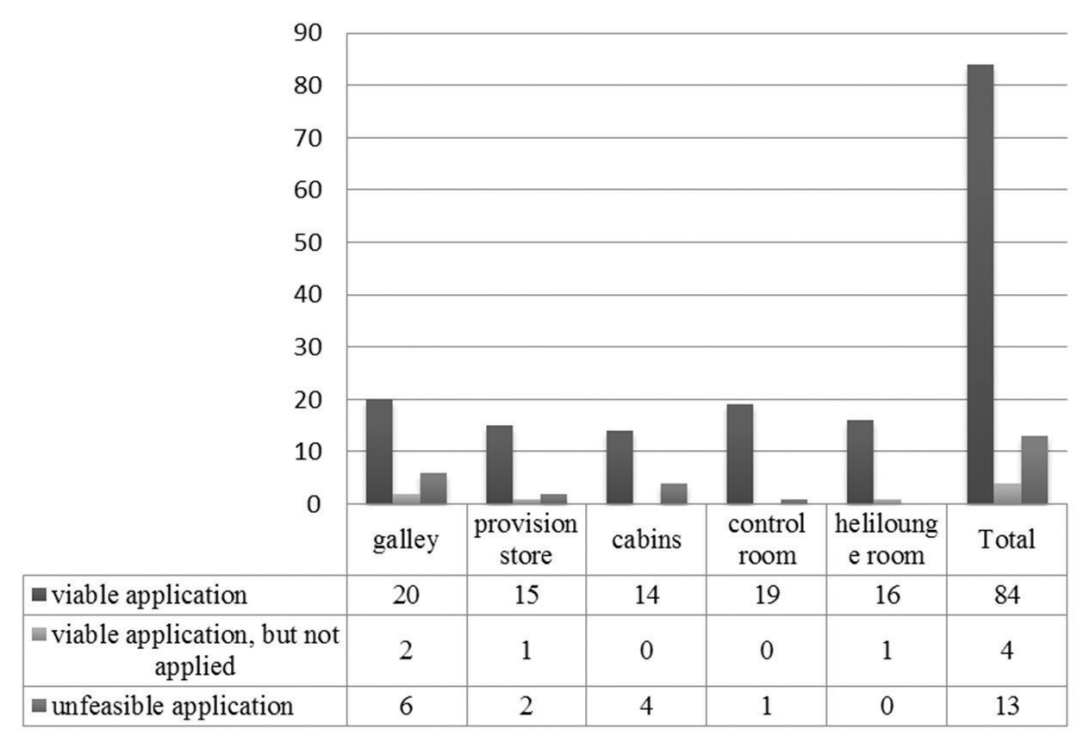

Figure 4. General mapping of the ergonomic recommendations used in the designs for the accommodation units - PROJ-A. 
the differences between the design contexts of the projects for the new platforms and for the reference situations from the previous study.

An important aspect of the TRs was the availability of information related to typical situations of environment use, equipment and furnishings, in the form of the configurations of use, which contribute towards understanding actual work activities, and which function as a guide for designers during the creation of the solutions adopted, yet do not limit possible solutions, as shown with the examples above.

\section{Final considerations}

Over the design process of PROJ-A and PROJ-B, one can see that the ergonomic study's layout proposals were negotiated amongst the various participants in the process, which meant that they were accepted by the oil company. Several adjustments to the layouts were made, meaning that the proposals were more likely to be implemented, and this characterised the detailing phase as one that involved considerable negotiation and exchange, both of which are typical characteristics of the early phases of a project (Martin, 1998, 2000).

However, a decisive factor that prevented some of the proposals from being implemented was precisely the phase of the project in which the ergonomic study became involved: the detailing phase, when part of the execution phase had already begun. Alterations made in these phases signify costs, and cost-cutting was one of the main objectives of the oil company's new philosophy. As observed in Duarte (2002), the late involvement of ergonomic team's results in a reduction of their abilities to contribute; the margins of manoeuvre for changes to the projects in this phase are very limited as most of the major decisions have already been taken. This makes it important for ergonomists to be involved at the earliest possible phases of the design process as the later the ergonomic intervention, the lesser its impact. (Béguin, 2007). If ergonomics is integrated at the start of a project, or at an early phase of the basic design, management can consider the main options that make up the project, thus allowing a description and understanding of the inter-relationships between the different components of the project, and increasing the ability to plan for and to reduce uncertainties about the efficacy of future operations (Duarte, 2002) over its course.

There are some aspects of the use and application of the TRs by the designers that are particularly relevant. As seen in Wulff et al. (1999a, b) and Pagenhart \& Buset (1998) the following characteristics were observed:
The first aspect noted was that designers lack operational experience and information on the operational techniques and teams. In the case-study, the designers involved in the detailing phase had not often been actually aboard a platform, and some had never been aboard at all. The design decisions were based mainly on the technical specifications and norms of each discipline and on the experience of previous projects for other units, projects that were rarely evaluated after becoming fully functional.

Considering the present context, where several platform designs took place at the same time, and which leads to the need for outsourcing project teams to be able to cope with the volume of accumulated work, it is possible to see how problematic it is to take decisions on the basis of experience of previous projects, as this knowledge is itself lost with the changing subcontracted crews.

The difficulties resulting from this loss of accumulated experience by the design teams were clear when compared with the different solutions proposed by the designers involved in the projects of PROJ-A and PROJ-B. As the design of PROJ-B was worked on only shortly after that of PROJ-A and while the ergonomic study for PROJ-A was already ongoing, several solutions for the design of PROJ-B were great improvements on those proposed for PROJ-A.

Another aspect of note is that there is a conflict between the number of specifications and requirements for a project and the ability of the designers to understand, assimilate and adopt them all. In this sense, the ergonomic team's participation was vital so that the factors related to the demands of the work were considered. As well as the participatory dynamic of the planning meetings the ergonomists also became the "representatives" of the users/operators, despite the fact that these were also represented by future operators after the planning meetings had been implemented.

The difficulty of understanding and managing a large amount of information on a project, something common with other large-scale projects, can be confirmed through some of the particularities of this project. Although the TRs from the first study (Duarte et al., 2009a) were developed at the oil company's request, with the purpose of guiding the new platform designs and capitalising on the company's experience in this kind of project, the designers involved in the PROJ-A and PROJ-B designs, who were part of the team subcontracted for this purpose, had not up to that point used the material available in the company. The ergonomic study was contracted due to the oil company's contractual obligation to the subcontracted company responsible for the design detailing. However, even the oil 
company's own engineering team, which acted as overseer to the project, did not make use of the material that had been produced in the previous study. The opportunity to use the TRs arose only when the ergonomic study was initiated, as part of the ergonomics team had taken part in the previous project.

After the ergonomics team was hired, the designers involved recognised that in the ergonomics study and the TRs there was yet another series of requirements that needed to be met alongside the numerous other technical requirements of each design discipline. Although the importance of the installations being able to meet operational requirements was recognised, decisions tended to be taken principally in order to meet the technical and safety demands of each discipline. Additionally, as the ergonomic TRs had an instructive rather than a normative character, when faced with the natural pressures of the project's cost and deadline, they were only superficially considered.

It was only with the participatory dynamic that was created through the ergonomic study, and that was founded on multidisciplinary meetings, that the designers gradually understood the pertinence of the areas raised by the TRs and the need for looking more deeply at certain operational issues, so as to enable solutions to be more appropriate for operational requirements.

Although the TR files were considered overly long to read/become familiarised with at such an advanced phase of the project (the detailing and construction phase), the contextualization of the TRs through the configurations of use and the ergonomic study, or the "specialists", were fundamental in leading the ergonomic directives to being considered and implemented. As well as the effective participation of future users in the interdisciplinary group that was formed during the ergonomic study, the presence of ergonomists in the design team and the description of the characteristics of the work activities in the form of the configurations of use, made it possible to extend the transfer of experience of the operational context to the teams in the project through dialogue between those involved. The transfer of operational experience based on interpersonal communication - interdisciplinary meetings, with the participation of ergonomists and future users - was an approach that was clearly positive in the temporal context of the project (with tight deadlines) and made it possible for the designers to assimilate the operational context without the need to read the extensive TRs (Pagenhart \& Buset, 1998).

It is not going too far to say that while EWA is based on operational experience, it would be a contradiction to design ergonomic systems without recourse to this experience through every phase of the platform design and construction. Thus, reducing the participation and experience of users to simple information gathering, limited to a specific point in the design process, would mean that the TRs were no different from formal consultation procedures practised by other disciplines, such as work rationalization. This means that ergonomic specifications drawn up in the spirit of the ergonomics of activity in Duarte et al. (2009a) can only be efficient providing they do not create definitive constraints for the designers and ergonomists who together detail the new installations through a participatory approach, where know-how is represented by future users and ergonomists.

The issues relating to increases in time and cost, which always arise at the start of ergonomic interventions, can be countered by the gains that can be made with design solutions that are more suited to work requirements. Pagenhart \& Buset (1998) set out the main reasons for the transfer of operational experience to be considered in designs: (1) to avoid losses related to accidents and occupational illnesses; (2) to avoid losses represented by inadequate functionality and reduced efficiency; and (3) to avoid costs associated with modifications needed for installations. According to the authors, "the inadequate work environment is expensive". Accordingly, the use of operational experience, especially by the support of the users group, is an important resource for the development of projects in the consideration of future work.

One can also see from the work meetings that conflicts between directives, specifications and requirements of the different disciplines involved in a project are common, and there is a tendency to prioritise requirements related to technical and safety issues, as well as those with specific formulations and ready solutions. This situation is aggravated by the fact that large offshore projects tend to take place in a context of sizeable budgets and extremely tight deadlines, where the margin for error is minimum and the time allowed for revision and interdisciplinary integration is scarce.

The ergonomic intervention in the PROJ-A and PROJ-B designs had positive results, as the dynamic of the meetings created a space for negotiation and exchange between the range of disciplines involved, and new solutions were found through the participation and the commitment of all those involved.

\section{References}

Béguin, P. (1994). De l'individuel au collectif dans les activités avec instruments (Doctoral thesis). Laboratoire d'Ergonomie du CNAM, Paris. 
Béguin, P. (2007). O ergonomista, ator da concepção. In P. Falzon (Ed.), Ergonomia (pp. 317-330). São Paulo: Blucher.

Castro, 1. (2010). A capitalização da experiência do uso do ambiente construído. Contribuições da avaliação pósocupação e da análise ergonômica do trabalho: estudo de caso realizado em um hospital-dia VIH (Tese de doutorado). Universidade Federal do Rio de Janeiro, Rio de Janeiro.

Conceição, C., \& Duarte, F. (2010). Contribution of ergonomics to workspace sesign in the offshore accommodations module. In SPE International Conference on Health, Safety and Environment in Oil and Gas Exploration and Production held, Rio de Janeiro. http://dx.doi. org/10.2118/127216-MS

Conceição, C. (2011). Do uso para o projeto: a transferência da experiência operacional para a concepção de espaços de trabalho em plataformas offshore (Tese de doutorado). Universidade Federal do Rio de Janeiro, Rio de Janeiro.

Cordeiro, C. (2003). Entre o projeto e o uso a colaboração da ergonomia na etapa de execução da obra (Tese de doutorado). Universidade Federal do Rio de Janeiro, Rio de Janeiro.

Daniellou, F., \& Garrigou, A. (1991). Human factors in design: sociotechnics or ergonomics? In M. Helander (Ed.), Design for manufactorability and process planning (pp. 55-63). Londres: Taylor \& Francis.

Duarte, F. (1994). A análise ergonômica do trabalho e a determinação de efetivos (Tese de doutorado). Universidade Federal do Rio de Janeiro, Rio de Janeiro.

Duarte, F. (2002). Complementaridade entre ergonomia e engenharia em projetos industriais. In F. Duarte (Org.), Ergonomia e projeto na indústria de processo contínuo. Rio de Janeiro: Lucerna.

Duarte, F., Lima, F., Remiro, R., \& Maia, N. (2008). Situations d'action caracteristiques et configurations d'usage pour la conception. In Actes du $43^{\circ}$ Congrès de la SELF, França.

Duarte, F., Andrade, R., Lima, F., Jackson Filho, J., Paradela, T., Cordeiro, C., Silva, G., Conceição, C., \& Remiro, R. (2009a). A integração da ergonomia ao projeto de plataformas offshore: recomendações técnicas. Módulo de acomodações. Rio de Janeiro.

Duarte, F., Lima, F., Remiro, R., \& Maia, N. (2009b). Settings of usage for the design process. In: Proceedings of the 17th World Congress on Ergonomics, Beijing.

Duclos, D. (1991). L'homme face au risque technique. Paris: L'Harmattan.

Garrigou, A., Carballeda, G., \& Daniellou, F. (1994). The contribution of activity analysis to the understanding of maintenance difficulties in high-risk process control plant. In F. Aghazadeh, Advances in Industrial Ergonomics and Safety VI (pp. 199-206). London: Taylor \& Francis.

Grandjean, E. (1998). Manual de ergonomia. Porto Alegre: Artes Médicas.
Guérin, F., Laville, A., Daniellou, F., Duraffourg, J., \& Kerguelen, A. (2001). Compreender o trabalho para transformá-lo: a prática da ergonomia. São Paulo: Blucher.

lida, 1. (1990). Ergonomia: projeto e produção. São Paulo: Blucher, 1990

De Keyser, V., Cortis, F. de, \& Daele, A. van. (1988). The approach of francophone ergonomy: studying new technologies. In V. Keyser, T. Quale, B. Wilpert \& S. A. Ruiz Quintilla (Eds.), The meaning of work and Technological options. London: John Willey \& Sons. PMCid:PMC1050468

Llory, M. (1996). Accidents industriels: le coût du silence. Paris: L'Harmattan.

Maline, J. (1994). Simuler le travail. Paris: ANACT.

Martin, C. (1998). La Conception architecturale entre volonté politique et faisabilité technique. le positionnement de l'intervention ergonomique (Doctoral thesis). Université Victor Segalen Bordeaux, France.

Martin, C. (2000). Maîtrise D'Ouvrage, Maîtrise D'ouvre construire un Vrai Dialogue: la Contribuition de L'Ergonome à la Conduite de Projet Architectural. Toulouse: Octarès.

Neuville, J. P. (1997). Le modèle japonais à l'épreuve des faits. Paris: Economica.

Pagenhart, A., \& Buset, H. (1998). Experience transfer from operational environments to instalation design: why, how and what. In Conferência Internacional de Saúde, Segurança e Meio Ambiente, Caracas.

Rabardel, P. (1995). Les hommes et les technologies: approche cognitive des instruments contemporains. Paris: Armand Colin.

Salvendy, G. (1982). Handbook of human factors. New York: John Wiley \& Sons.

Schön, D. (2000). Educando o profissional reflexivo: um novo design para o ensino e a aprendizagem. Porto Alegre: Artmed.

Westgaard, R., \& Wulff, U. (1991). Ergonomic acceptability criteria for Norwegian Offshore Industry. In Proceedings of the 1th International Conference on Health, Safety \& Environment in Oil and Gas and Production, Holanda.

Wisner, A. (1990). La méthodologie em ergonomie: d'hier à aujourd'hui. In $26^{\circ}$ Congrés de la SELF, Montreal.

Wulff, 1., Westgaard, R., \& Rasmussen, B. (1999a). Ergonomic criteria in large-scale engineering design: 1 management by document only? Formal organization VS. designers perceptions. Applied Ergonomics, 30, 191-205. http:// dx.doi.org/10.1016/S0003-6870(98)00029-5

Wulff, 1., Westgaard, R., \& Rasmussen, B. (1999b). Ergonomic criteria in large-scale engineering design: 11 evaluating and applying requirements in the real world design. Applied Ergonomics, 30, 207-221. http://dx.doi. org/10.1016/S0003-6870(98)00030-1 